\title{
Coagulant Dipping Time and Temperature Optimisation for Latex Glove Uneven Coating Investigation
}

\author{
Loong Than ${ }^{1,}$ Siew Wei Phang ${ }^{1, *}$, Kin Nam $\mathrm{Ho}^{2}$ \\ ${ }^{1}$ School of Engineering, Taylor's University, Subang Jaya, Selangor, Malaysia \\ ${ }^{2}$ TG Medical Sdn Bhd, Factory 14, Klang, Selangor, Malaysia.
}

\begin{abstract}
Powdered glove is produced by natural latex with the aid of coagulant. The composition of the coagulant contains wetting agent, calcium nitrate as coagulant and anti-tack agent. Generally wetting agent causes foam and results in uneven wall thickness in glove production. Hence, the objective of this research was to select a suitable wetting agent sample that could be used by the production, as well as optimising the parameter such as temperature of coagulant, weight percentage of wetting agent and coagulant dipping time to reduce the rejection of uneven thickness. This paper presented the preliminary testing including foam height test, cloud point test, wetting agent characterisation and the samples mechanical analysis. Two setting agents (sample $\mathrm{T}$ and sample E) were chosen due to its availability in the production line. Throughout the wetting agent characterisation, sample $\mathrm{T}$ was preferred compared to sample $\mathrm{E}$ due to similar bonding of the wetting agent. The surface tension of coagulant and tensile strength of glove samples meet the glove industry standard at the variation of wetting agent amount. The optimise parameter were at $0.0175 \mathrm{wt} \%$ of wetting agent and 5 seconds dipping time at $63{ }^{\circ} \mathrm{C}$. The average thickness of the gloves at this parameter was at $0.09 \pm 0.004$ $\mathrm{mm}$ which is at the acceptable level comparing to $0.1 \mathrm{~mm}$ thickness of ASTM standard.
\end{abstract}

\section{Introduction}

In order to remain competitive in the market, organisations look for ways to improve their production and management processes, including but not limited to reduction in production cost, enhance productivity and improve product quality. In other words, organisations must utilise all the available resources efficiently and effectively to cater their customers with high quality products at a low price. Uneven wall thickness has been an issue in the glove manufacturing industry. It has led to several severe rejections in the production line including glove pin-hole, reduction in mechanical properties, and the thin area defect or normally known as "fish-eye" defect as shown in Fig. 1. The uneven thin area defect is mainly due to the present of uneven adherence of latex on the mould former.

\footnotetext{
${ }^{1}$ Corresponding author: eunicepsw@gmail.com
} 


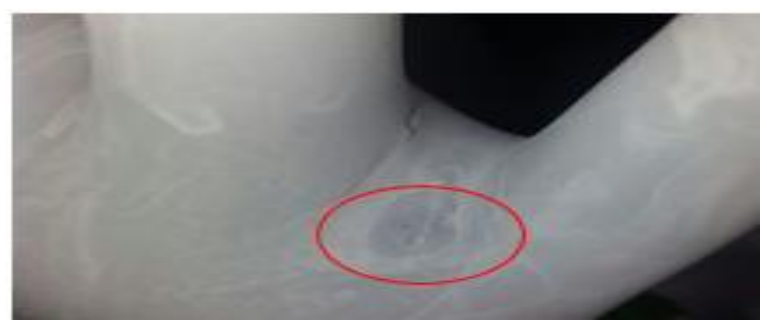

Fig. 1 Fisheye defect located in powdered glove.

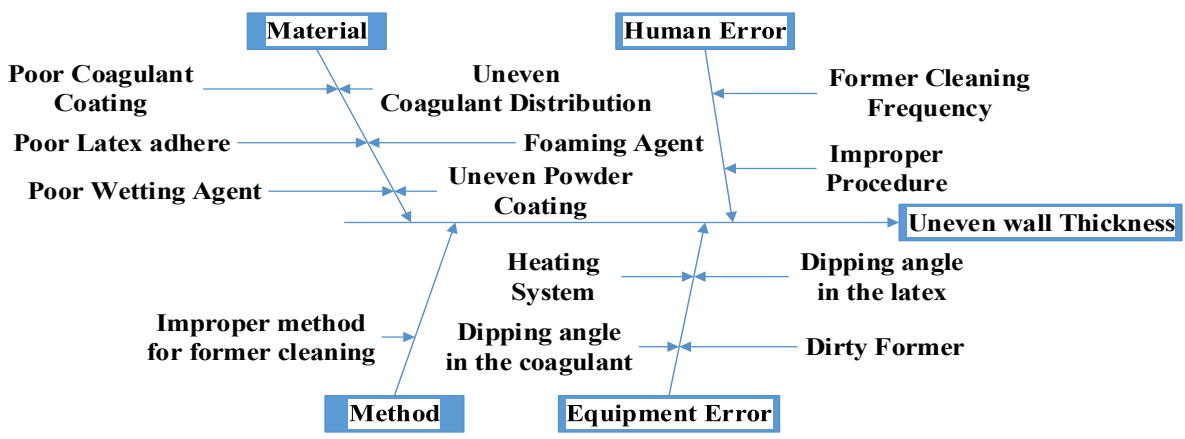

Fig.2 Ishikawa diagram for uneven thickness of glove [1].

Fig. 2 shows the potential causes of the uneven thickness of the gloves, in which includes human error, the materials (mainly chemicals), and / or the improper process method. In the "material" factor, poor coagulant wetting on formers causes the jagged coagulant allocation, that leads to poor latex pick up during dipping in latex process, which resulted in forming a curve shape in the product after inflation and during usage [1]. Besides, insufficient cleaning of the former may also lead to similar defect [2].

Wetting agent is also known as surfactant, where the concentration of the chemical affects the thickness of the glove [3]. The main purpose of the wetting agent is to reduce the surface tension of the coagulant to ensure even coating on the former. However, most wetting agents form layers of foam during the coagulant mixing process due to stirring at high RPM. This foam layer counters the main purpose of the wetting agent on even coating on the former by create areas of air pockets during the coagulant coating process. As a result, create more rejection of uneven thickness in gloves especially the thin area defect as shown in Fig. 1 [4]. This paper presented a preliminary study on the foam creation by different wetting agents, namely sample $\mathrm{T}$ and sample $\mathrm{E}$ (actual chemical mixture nondisclosed due to company confidentiality), the chemical coagulant dipping time and concentration, prior to process optimisation to reduce the thin area defect.

\section{Methodology}

\subsection{Pre-screen Test - Foam Heights Test}

The first screening test was to determine the root cause of the foam creation during the coagulant mixing process. The prepared coagulant was stirred at 600 RPM for at least 24 hours to ensure the homogeneity of the chemicals dispersion as well as avoid anti-tack 
agent, calcium carbonate's sedimentation. Small amount of wetting agent has known to be more effective in reduction of the coagulant's surface tension [4,5].

Coagulants samples were collected from the production line and different amount of the wetting agent, $0.005 \mathrm{wt} \%, 0.03 \mathrm{wt} \%$ and $0.05 \mathrm{wt} \%$, were added to the samples. One sample without wetting agent was taken as a control sample. The mixtures were then place in the mechanical stability tester, which stirred at $14000 \mathrm{rpm}$, and the foam heights were recorded.

\subsection{Pre-screen Test - Cloud Point Test}

Cloud point test was to investigate the temperature when the coagulant turned cloudy and lose its functionality as a coating agent. In nature, additional of anti-tack powder in the coagulant causes the mixture to be cloudy, hence, this test were conducted without additional of the anti-tack powder, to ensure the solutions were remain transparent at the beginning of the testing. Same amount of wetting agent were added to the coagulant mixture collected from the production line, with one without wetting agent as controlled sample. The samples were heated on the hot plate and the temperature of the solutions was recorded till the solution turned cloudy.

\subsection{Fourier Transform Infrared Spectroscopy (FTIR)}

Two wetting agent samples, sample E and sample T were tested using FTIR to studied its functional group. Since both of this sample are alcohol ethoxylate that consist of general chemical structure of $\mathrm{R}-\left(\mathrm{CH}_{2} \mathrm{H}_{2} \mathrm{O}\right)_{\mathrm{n}}-\mathrm{H}$; where $\mathrm{R}$ was referring to an alkyl group, which is hydrophobic in nature. While $-\left(\mathrm{CH}_{2} \mathrm{H}_{2} \mathrm{O}\right)_{n}$ - was referring to the ethylene oxide, a hydrophilic functional group. The higher number of ethylene oxide group present in the sample, it has a better efficiency in reducing the surface tension in the solution, but at the same time, creating more foams.

\subsection{Full Factorial Design}

Full factorial design was use a design of experiment tool to optimise the temperature of coagulant $\left(\mathrm{X}_{1}\right)$, weight percentage of wetting agent $\left(\mathrm{X}_{2}\right)$ and mould dipping time in the coagulant $\left(\mathrm{X}_{3}\right)$ to minimise the uneven thickness of the glove. A $3^{3}$ full factorial, which lead to a total of 27 formulations were designed.

\subsection{Glove Sample Preparation}

By refer to section 2.4, glove samples were prepared in lab dipping scale, which consist of four dipping tank (volume for $7 \mathrm{~kg}$ each). The first tank was filled with diluted acid; second tank was filled with coagulant with the designed wetting agent amount; 3rd tank of pure latex, and $4^{\text {th }}$ tank was filled with corn-starch. Lab scale hand former was used to prepare the samples. The former was dipped in the acid tank to clean up the residue and rince with water. Later, it was heated up to $60^{\circ} \mathrm{C} \pm 2^{\circ} \mathrm{C}$, followed by a dipping at the coagulant solution for about 2 minutes and dried at the $120^{\circ} \mathrm{C}$ for another 2 minutes. The formers were air-cooled to the range of $60-65^{\circ} \mathrm{C}$ and were dipped in the latex dispersion obtained from production for 15 seconds followed by a 15 minutes drying at $120^{\circ} \mathrm{C}$ [6]. Lastly, the formers were dipped in the last tank, coated with corn starch and left for cooling down to room temperature. Latex glove samples were then stripped from the mould. 


\subsection{Glove Sample Characterisation}

\subsubsection{Tensile Strength Tester and Sample Cutter}

Tensile testing was done following the ASTM D 412-80 test method using dumb bell shaped samples at a cross-head speed of $500 \mathrm{~mm} / \mathrm{min}$ with a Universal testing machine [7]. Table 1 shows the ASTM standard for the samples.

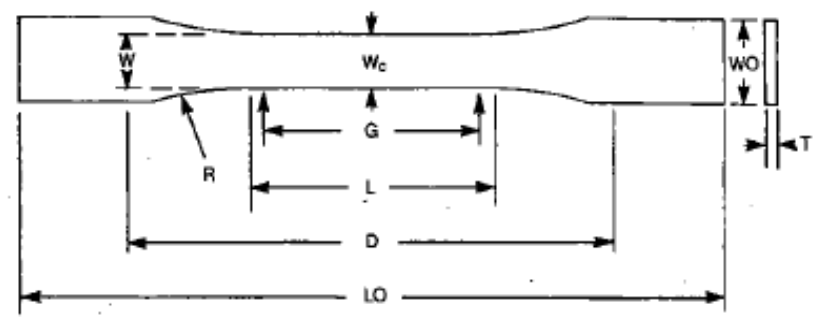

Fig. 3 ASTM plate shape cutting.

Table 1 ASTM standard.

\begin{tabular}{|c|c|}
\hline Dimension & Unit, $\mathrm{mm}$ \\
\hline Width of narrow section (W) & 6 \\
\hline Length of narrow section (L) & 33 \\
\hline Width overall (WO) & 19 \\
\hline Length overall (LO) & 115 \\
\hline Gage length (G) & 25 \\
\hline Distance between grips (D) & 65 \\
\hline Radius of fillet (R) & 14 \\
\hline Outer Radius (RO) & 25 \\
\hline
\end{tabular}

\subsubsection{Thickness Gauge Test}

The thickness of the samples was measured using Vernier Caliper. Based on industrial glove standard, the average thickness of the glove is at $0.1 \mathrm{~mm}$. The measurement was at the area of the palm, areas between fingers such as between thumb with first finger, between first finger with second finger, between second finger with third finger and between third fingers with fourth finger.

\subsection{Surface Tension Test}

The coagulant of each combination with wetting agent was collected during the glove sample preparation, and was analysed with surface tension meter DST-60. 


\section{Result and Discussion}

\subsection{Analysis of First Pre - Screen test}

Fig. 4 shows the result of the foaming heights measurement at different wetting agent $w t \%$. It shows that increment in amount of wetting agent in coagulant causes higher the foam height formed. No foam forming in the controlled sample without the wetting agent. The uneven thickness between fingers was found caused by webbing foam on the area during coagulant dipping. When the webbing foam rupture, it leads to no or too little coating of calcium nitrate on the former, which produce thin area of the latex film.

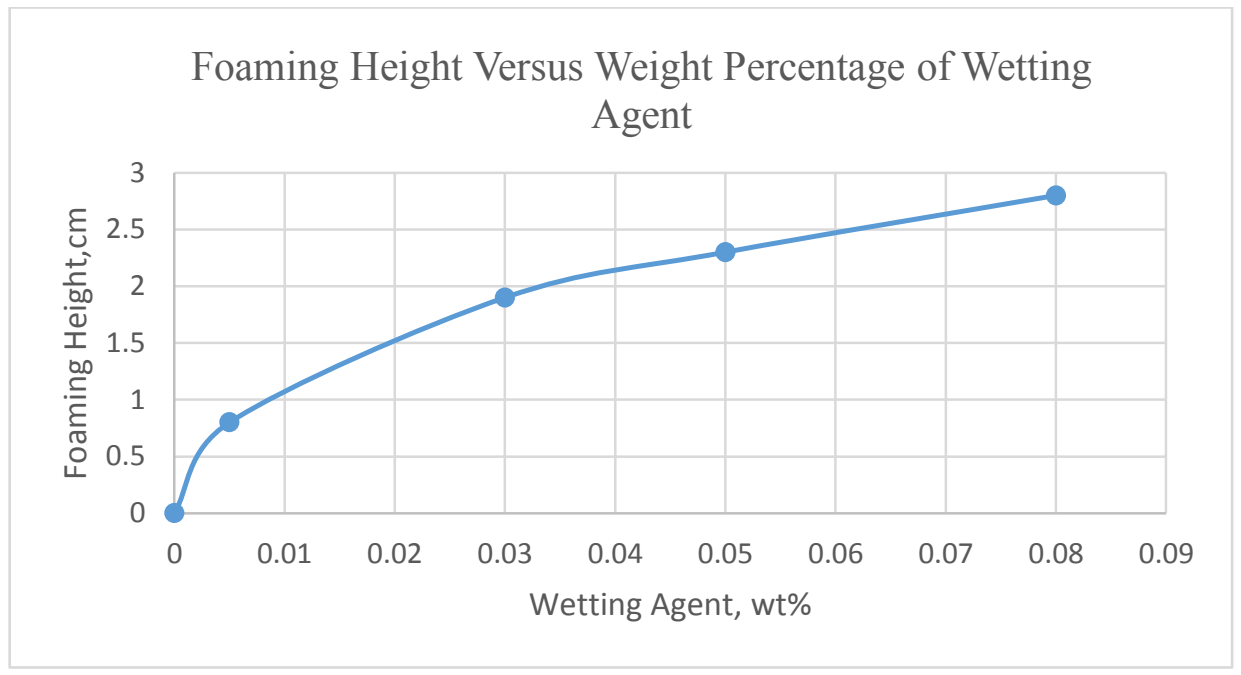

Fig. 4 Foaming Height versus Weight Percentage of Wetting Agent.

\subsection{Analysis of Second Pre - Screen test}

The cloud point analysis was to determine the effective coagulants' temperature range for the optimisation process, as when the chemical reaches its cloud point, the coagulant loses its functionality as the coating agent for latex solution. Therefore the design temperatures have to be lowered than the tested cloud point temperature. From Table 2, sample $\mathrm{E}$ and sample $\mathrm{T}$ both proven to have the cloud point above $80^{\circ} \mathrm{C}$. This concludes that the designed temperature in between $58^{\circ} \mathrm{C}$ to $68^{\circ} \mathrm{C}$ was safe to be tested.

Table 2 Cloud Point Test result

\begin{tabular}{|c|c|c|c|}
\hline Chemical & $\begin{array}{c}\text { Weight Percentage of } \\
\text { wetting agent, } \%\end{array}$ & $\begin{array}{c}\text { Cloud Point for Sample } \\
\mathrm{E},{ }^{\circ} \mathrm{C}\end{array}$ & $\begin{array}{c}\text { Cloud Point for Sample } \\
\mathrm{T},{ }^{\circ} \mathrm{C}\end{array}$ \\
\hline Coagulant & 0 & No Cloud Point & No Cloud Point \\
\hline Coagulant & 0.005 & More than $80^{\circ} \mathrm{C}$ & More than $80^{\circ} \mathrm{C}$ \\
\hline Coagulant & 0.03 & More than $80^{\circ} \mathrm{C}$ & More than $80^{\circ} \mathrm{C}$ \\
\hline
\end{tabular}




\begin{tabular}{|c|c|c|c|}
\hline Coagulant & 0.05 & More than $80^{\circ} \mathrm{C}$ & More than $80^{\circ} \mathrm{C}$ \\
\hline Coagulant & 0.08 & More than $80^{\circ} \mathrm{C}$ & More than $80^{\circ} \mathrm{C}$ \\
\hline
\end{tabular}

\subsection{Analysis of Third Pre - Screen test}

This test was to determine the bonding of the wetting agent. Since both sample E and T are alcohol ethoxylate, there is possibility of the wetting agent to be having similar bonding. The screening is necessary as 27 runs of full factorial design consume a large amount of time for glove sample preparation.

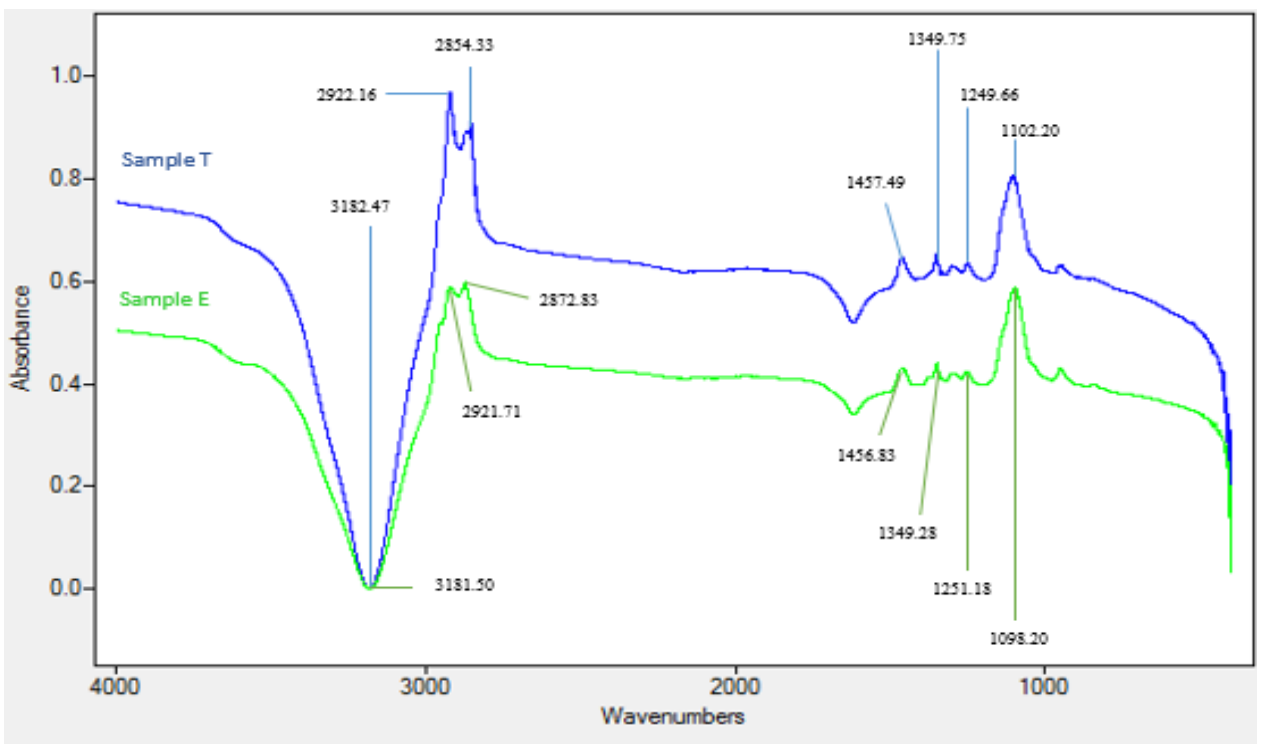

Fig. 5 FTIR Spectrum of both samples

Based on Fig. 5, the first zone section of sample T, there is $U$ shape peak that located about $3182.47 \mathrm{~cm}^{-1}$ which in between $2650 \mathrm{~cm}^{-1}$ to $3200 \mathrm{~cm}^{-1}$. This U shape peak is broad and strong that would represent the $\mathrm{OH}$ - group. On the zone 2, second peak is about $2872.79 \mathrm{~cm}^{-1}$ and $2854.33 \mathrm{~cm}^{-1}$ is refer to alkyl group or $\mathrm{CH}_{3}$ - which is in between $2960 \mathrm{~cm}^{-1}$ to $2850 \mathrm{~cm}^{-1}$. On the fingerprint zone, peak at $1457.49 \mathrm{~cm}^{-1}, 1349.75 \mathrm{~cm}^{-1}$ and $1249.66 \mathrm{~cm}^{-1}$ are methylene or $-\mathrm{CH}_{2}[8]$.

While peak at $1102.20 \mathrm{~cm}^{-1}$ is refer to ether group or -C-O-. While based on spectrum of sample $\mathrm{E}$, in the first zone section, the $U$ shape peak that located about $3181.50 \mathrm{~cm}^{-1}$ that lies in between $2650 \mathrm{~cm}^{-1}$ to $3200 \mathrm{~cm}^{-1}$. This peak is broad and strong that represent the $\mathrm{OH}$ - group. While on the zone 2, second peak is about $2921.71 \mathrm{~cm}^{-1}$ and $2872.83 \mathrm{~cm}^{-1}$ is refer to alkyl group or $\mathrm{CH}_{3}$ - that lies in $2960 \mathrm{~cm}^{-1}$ to $2850 \mathrm{~cm}^{-1}$. Lastly on the fingerprint zone, peak at $1456.83 \mathrm{~cm}^{-1}, 1349.28 \mathrm{~cm}^{-1}$ and $1251.18 \mathrm{~cm}^{-1}$ are methylene or $-\mathrm{CH}_{2}$. While peak at $1098.20 \mathrm{~cm}^{-1}$ is refer to ether group or -C-O-. With both of the sample spectrum is shown in Fig. 5, it shows that both of the samplse of wetting agent is similar in term of bonding. This shows that sample $\mathrm{T}$ have more of hydrophilic and hydrophobic bonding compare to Sample E due to absorbance value is higher which mean the finger print zone of sample $\mathrm{T}$ have more ethylene oxide group. Ethylene oxide group in alcohol ethoxylate is the role that promotes foam and surface tension reduction properties. As a result, sample $\mathrm{T}$ promote more foam and reduce more surface tension compare to sample E. Besides, sample $\mathrm{T}$ was more readily available in market compared to sample E. Hence, sample E was removed. 


\subsection{Analysis of Surface Tension}

Based on the coagulant with varies of wetting agent amount, Fig. 6 below shows the decreases trends of the surface tension on coagulant with the increase of wetting agent. This test was to verifying the coagulant that needs to be within the standard of the typical surface tension of the coagulant. The typical surface tension of coagulant is about 0.001 $\mathrm{N} / \mathrm{m}$ to $0.040 \mathrm{~N} / \mathrm{m}$. Based on the Fig. 6 , the coagulant without the wetting agent is having greater surface tension which is $0.0486 \mathrm{~N} / \mathrm{m}$. This means that the coagulant is not suitable for glove sample preparation. While with the small amount of the $0.005 \mathrm{wt} \%$ wetting agent added, the surface tension is about $0.04 \mathrm{~N} / \mathrm{m}$.

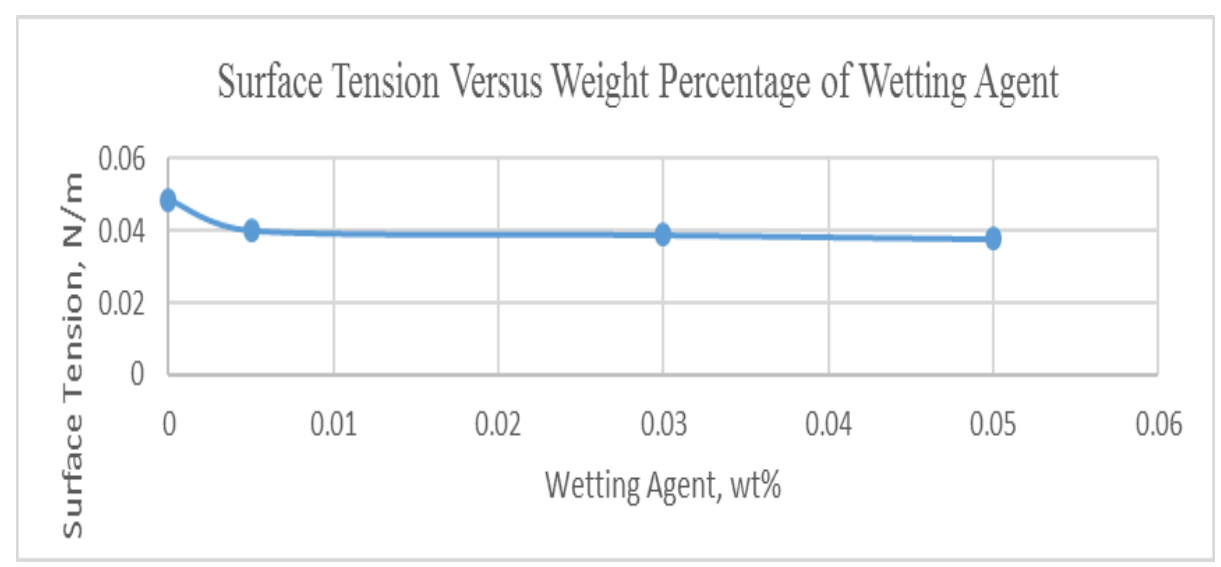

Fig. 6 Surface Tension versus Weight Percentage of Wetting Agent

\subsection{Analysis of Glove Sample Characterisation}

After the glove sample that have prepared, glove weight, glove thickness and its tensile strength are require to be studied so that optimisation on the parameter can be determined. With the result being collected, it can make use of Matlab ${ }^{\circledR}$ software to plot the surface plot with colour bar as parameter to be studies. With the response surface methodology, optimisation of the production can be done.

\subsubsection{Tensile Strength Analysis}

Based on Fig. 7, the tensile strength against temperature and dipping time met the requirement of the standard at $18 \mathrm{MPa}$ which shown based on the colour bar. 


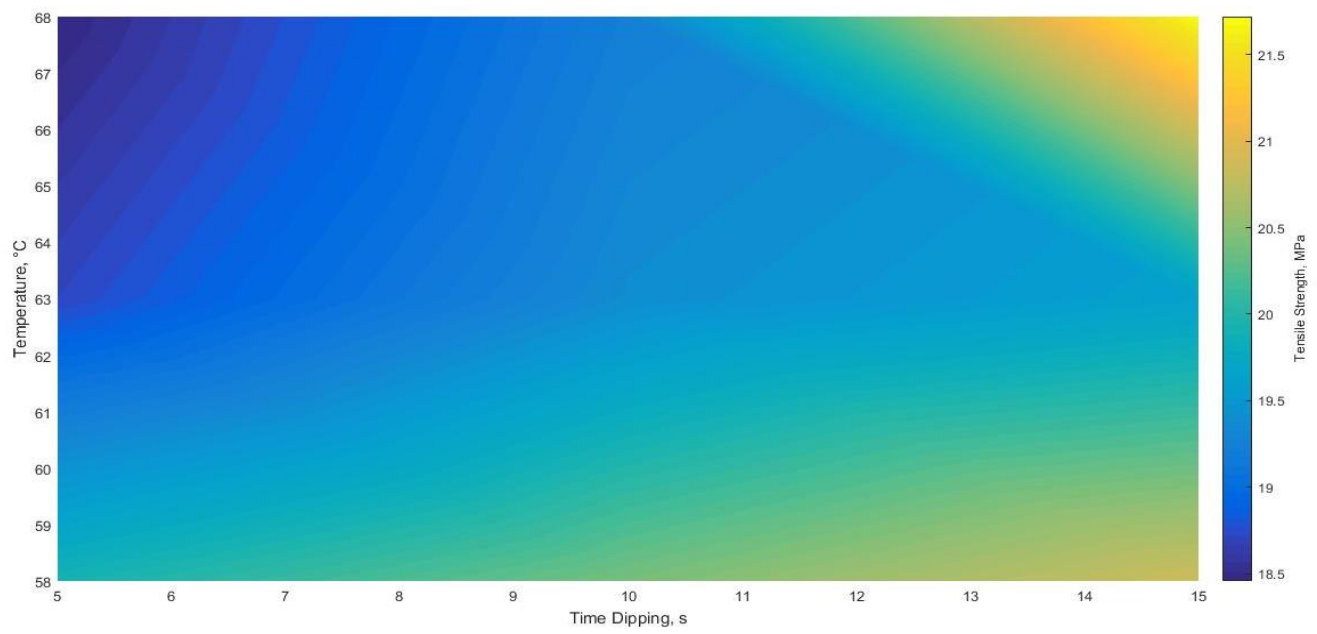

Fig. 7 Contour of temperature and time against tensile strength of glove for $0.005 \mathrm{wt} \%$ of wetting agent

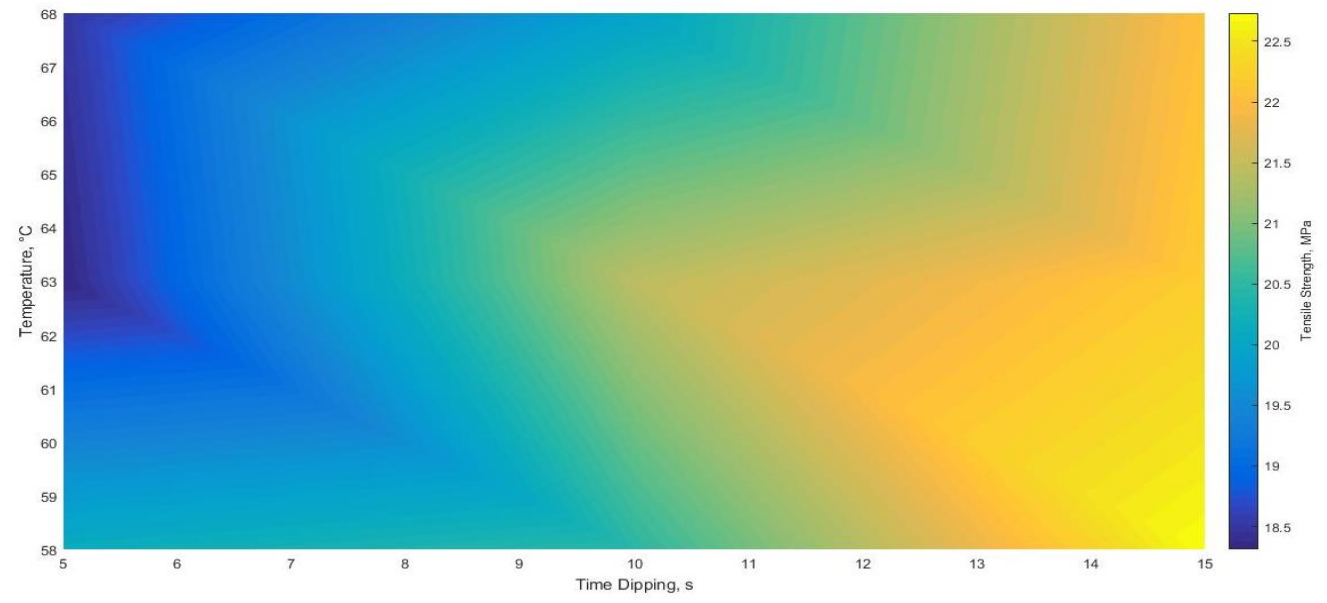

Fig. 8 Contour of temperature and time against tensile strength of glove for $0.03 \mathrm{wt} \%$ of wetting agent 


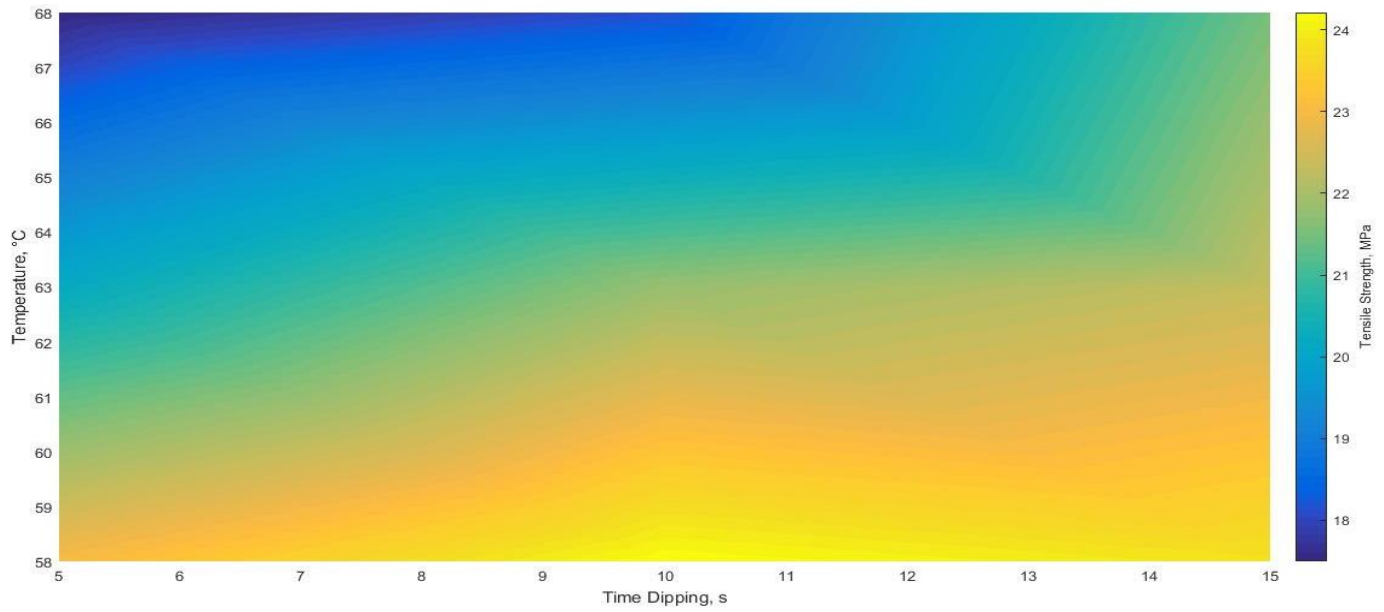

Fig. 9 Contour of time and temperature against tensile strength of glove for $0.05 \mathrm{wt} \%$ of wetting agent

In Fig. 7, the glove sample prepared at $0.005 \mathrm{wt} \%$ of wetting agent. The glove that produce on at temperature range from $58^{\circ} \mathrm{C}$ to $68^{\circ} \mathrm{C}$ as well as the range of time dipping of 5 seconds to 15 seconds meet the standard requirement of the tensile strength. While at temperature of $63^{\circ} \mathrm{C}$ and 15 seconds, tensile strength should have about $20 \mathrm{MPa}$ and above. Based on observation, whenever the temperature of the coagulant is low such as $58^{\circ} \mathrm{C}$, the coagulant is hardly evaporating on the surface of the mould. This resulted the coagulant to be flowing on the mould instead of dried where the mould is having smooth surface. If the mould does not have smooth surface which allow forming of thin film without any restrain and would not dripped off. This provides coagulant to adhere on the surface with a thicker film and provide higher tensile strength as well. By referring to Fig. 8, coagulant is hardly evaporating at $58^{\circ} \mathrm{C}$ and this allows the area on the mould that to have lesser amount of coagulant. Hence, the glove tensile strength should be lowered at lower temperature. This means that there is fluctuation in reading where it is actually require more glove sample so that the glove reading would be consistent.

While based on Fig. 8, the glove sample is tested at $0.03 \mathrm{wt} \%$ of wetting agent. Based on the colour of the contour, it shows that the tensile strength against temperature and dipping time is again meeting the requirement of the standard at $18 \mathrm{MPa}$. Since the tensile strength does not varies much compare from $58^{\circ} \mathrm{C}$ to $68^{\circ} \mathrm{C}$, more glove sample are required to be studied so that to allow consistent reading. Based on the Fig. 9, the tensile strength of the glove at $58^{\circ} \mathrm{C}$ is greater than $68^{\circ} \mathrm{C}$. This is basically not supposed to be happened theoretically and the result should be other way around. The reason of this difference of tensile strength is due to the dipping time for latex is not consistent that may due to allow the glove tends to be thicker. This resulted at $58^{\circ} \mathrm{C}$ to have higher tensile strength.

\subsubsection{Thickness Glove Analysis}

On the other hand of glove thickness, it is the most crucial part as it determines the uneven wall thickness. The glove manufacturing standard of the powdered glove thickness is at $0.1 \mathrm{~mm}$. 


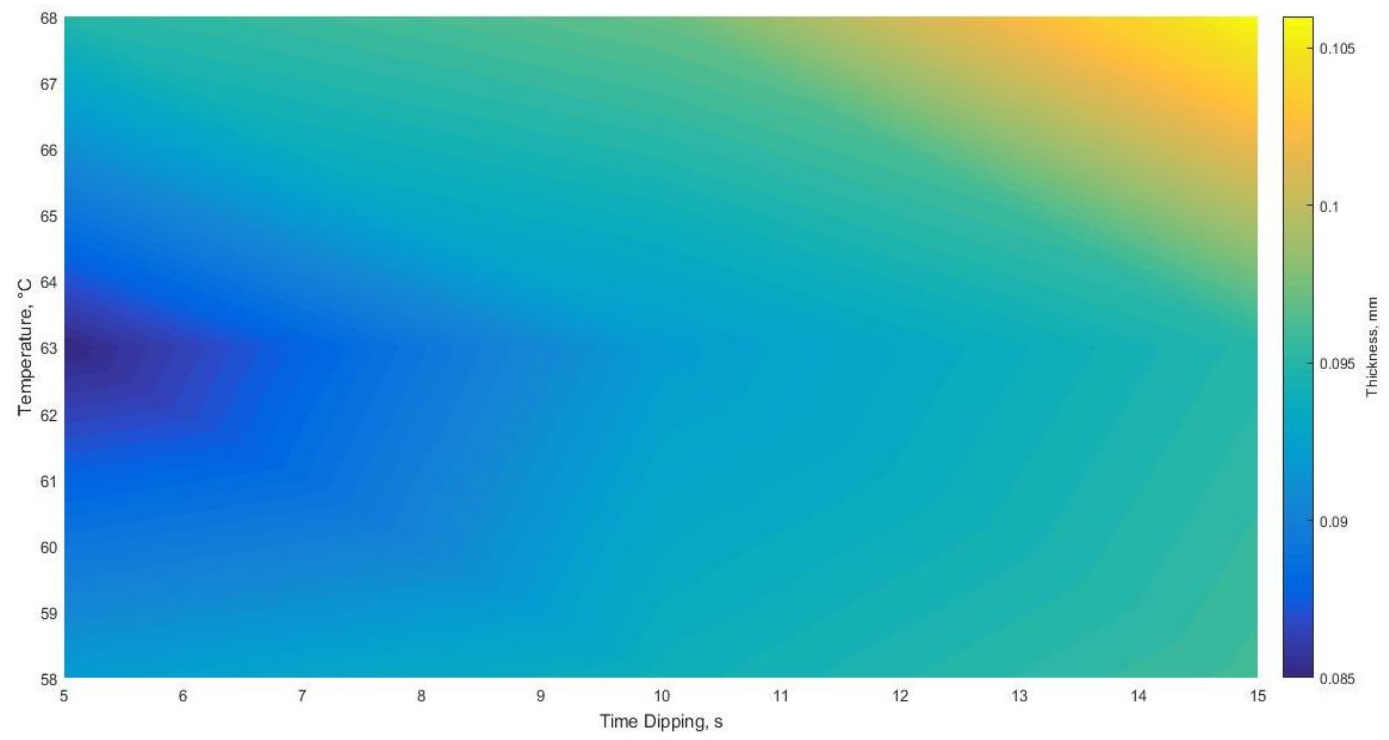

Fig. 10 Contour of time and temperature against glove thickness for $0.005 \mathrm{wt} \%$ of wetting agent.

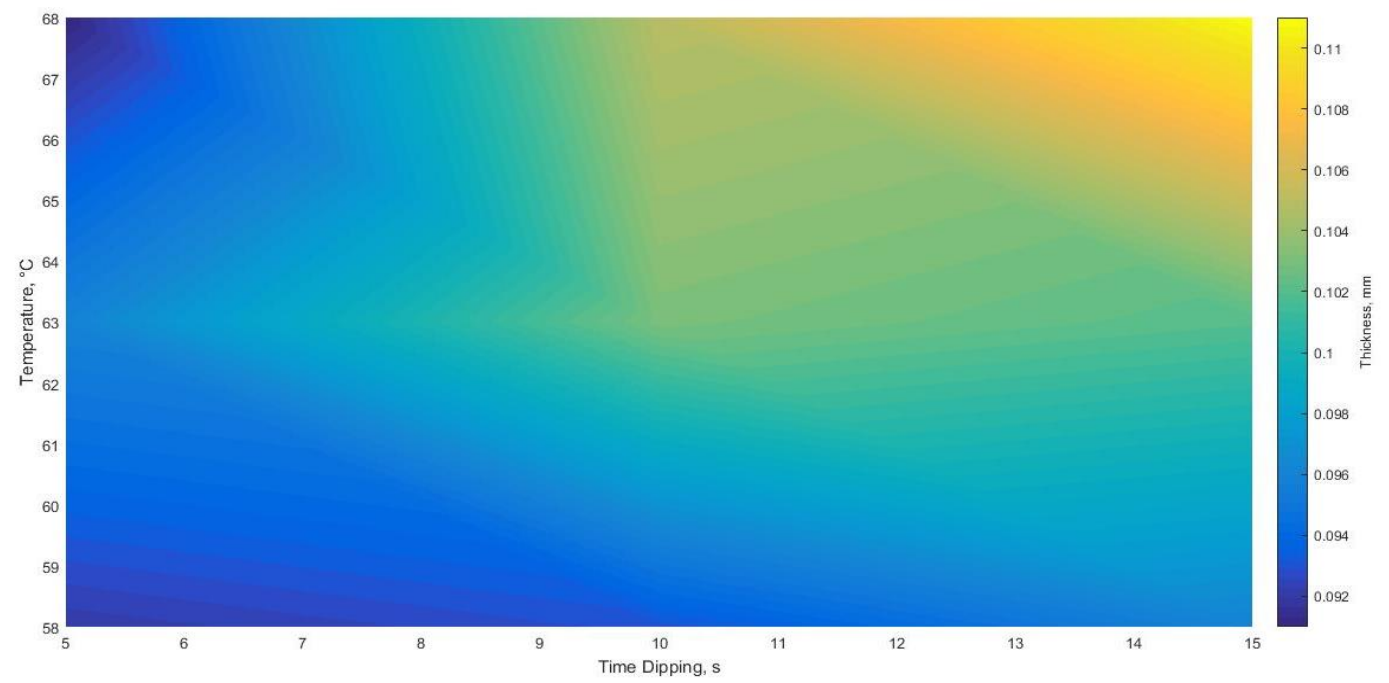

Fig. 11 Contour of time and temperature against glove thickness for $0.03 \mathrm{wt} \%$ of wetting agent 


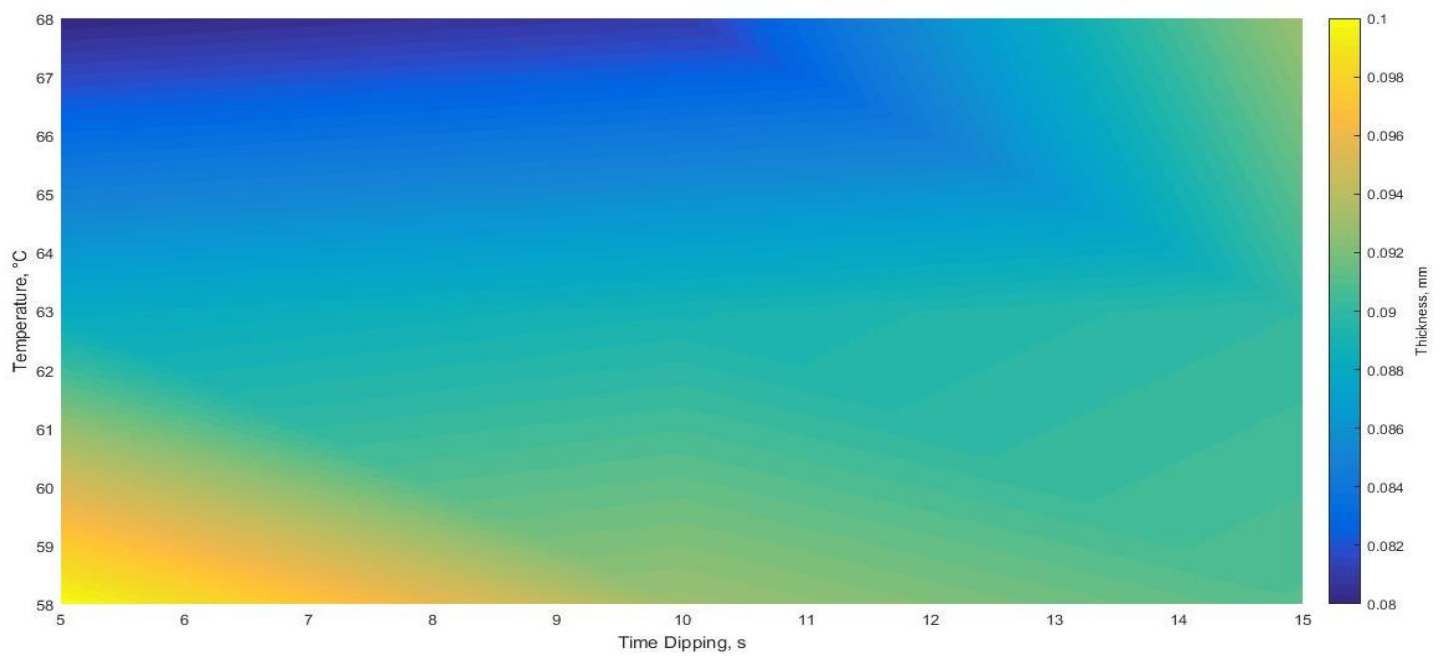

Fig. 12 Contour of time and temperature against glove thickness for $0.05 \mathrm{wt} \%$ of wetting agent

Refer to the Fig. 10, the colour bar shows the coagulant temperature at about $63^{\circ} \mathrm{C}$ with 6 seconds dipping time. This enable to achieve the $0.1 \mathrm{~mm}$. Besides, at $68^{\circ} \mathrm{C}$ with 8 seconds dipping time also able to achieved the $0.1 \mathrm{~mm}$. Moreover, this Fig. 11 shows that the trend where thickness increases with the dipping time of the coagulant which is synchronise with the concept that mention previous section. Based on Fig. 15 , temperature at $66^{\circ} \mathrm{C}$ until $68^{\circ} \mathrm{C}$ with 12 to 15 seconds able to achieve thickness of $0.1 \mathrm{~mm}$. This result is not able to be applied in production line. This is because process line operate at high speed where 12 to 15 seconds is not able applicable. By comparing Fig. 11 and Fig. 12, Fig. 12 should have better performance as $0.03 \mathrm{wt} \%$ wetting agent basically able to coat on the mould better than $0.005 \mathrm{wt} \%$.

However, more amount of wetting agent would create more foam and bubble on the mould. Based on observation, the coagulant of wetting agent at $0.03 \mathrm{wt} \%$ and $0.05 \mathrm{wt} \%$ are having large amount of bubble compared to $0.005 \mathrm{wt} \%$ wetting agent. This can be shown in Fig. 13. The reason that the coagulant need to be agitate constantly due to avoid the antitack agent to be sediment.

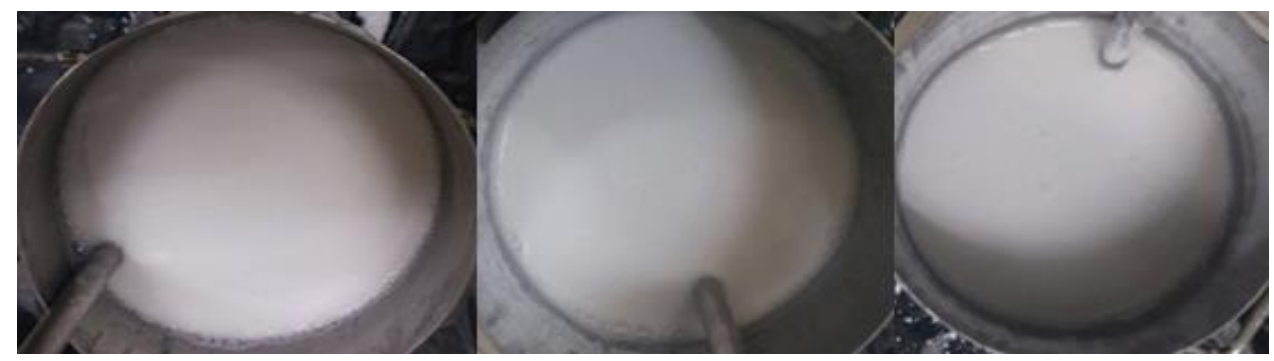

Fig.13 Wetting agent at $0.005 \mathrm{wt} \%$ (left), $0.03 \mathrm{wt} \%$ (middle) and $0.05 \mathrm{wt} \%$ on the (right)

The Fig. 14 show the foam on the mould that affect the on the latex dipping. With this reason, the tensile strength of the glove is also affected by this foam that can compare Fig. 8 and Fig. 11. Also, higher temperature of the coagulant able to break the foam compared 
to the lower temperature as shown in Fig. 10 and Fig. 11. As a result, lower surface tension liquid would allow bubble foam of liquid would be larger. Hence, increase in liquid drainage and lead bubble to rupture during withdrawing of mould after coagulant dipping. While at lower temperature, it would have higher viscosity that allow the bubble to retain is shape for a longer period. Besides, the bubble foam would having smaller bubble compare to higher temperature and liquid drainage tendency would be lower. As a result, the foam does not rupture. While this foam would only rupture during the drying process of coagulant in oven. This means that the rupture of foam in the certain area in oven will have less deposited of calcium nitrate. Hence, thickness of glove is affected.

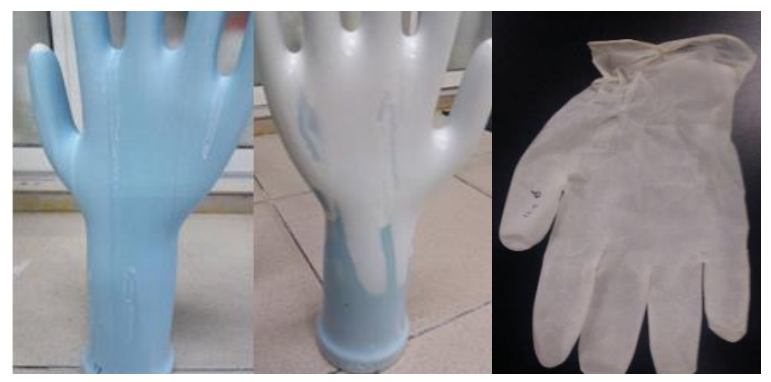

Fig.14 Foam on the mould (Left) and Latex uneven coating (Middle) and Sticky Glove at the cuff area (Right)

Based on Fig. 14, the foam height at $0.05 \mathrm{wt} \%$ is greater than $0.005 \mathrm{wt} \%$ and $0.03 \mathrm{wt} \%$ where it could be refer to Fig. 4. This shows $0.05 \mathrm{wt} \%$ have the foam issue that similar to wetting agent at $0.03 \mathrm{wt} \%$ that can be based on Fig. 14. But $0.05 \mathrm{wt} \%$ wetting agent is having more serious issue where there is presence of webbing that happen between the thumb and first finger. Even though higher temperature expected to reduce the foam creation but there was too much wetting agent in this sample. A higher temperature is required to break more foam and more glove sample is require for consistent reading.

At $0.005 \mathrm{wt} \%$ wetting agent, the glove sample having issue of sticky where anti-tack agent is not disperse well enough. This is due to wetting agent is used to ensure a better coating effect on the mould. While wetting agent at $0.03 \mathrm{wt} \%$ and $0.05 \mathrm{wt} \%$, the glove also the issue of sticky glove where located at the foam area during coagulant dipping.

\subsection{Analysis of Response Surface Methodology Result}

Since the result of the tensile strength on Fig. 7, Fig. 8 and Fig. 9 show a positive result. It narrowed the optimisation range of the glove thickness. The best parameter of the glove sample was at $63^{\circ} \mathrm{C}$ with 6 seconds dipping time and $68^{\circ} \mathrm{C}$ with 8 seconds dipping time. Both of this parameter gave $0.1 \mathrm{~mm}$ thickness with $0.005 \mathrm{wt} \%$. But at $0.005 \mathrm{wt} \%$, the glove tends to be sticky. Hence, more wetting agent is require so that anti-tack agent able to disperse evenly. Based on Fig. 15 below, by choosing the parameter $63^{\circ} \mathrm{C}$ with 6 seconds dipping time would be wise as lower temperature would have lower operating cost for the coagulant. While lesser dipping time that is 6 seconds would have a better profit in glove production compare to 8 seconds. This is due to lesser time require to produce the glove sample. As a result, fixing the temperature at $63{ }^{\circ} \mathrm{C}$ and making variation of the wetting agent amount and dipping time would the final optimisation. The optimisated parameter was at $0.0175 \mathrm{wt} \%$ of wetting agent and about 5 seconds dipping time at $63{ }^{\circ} \mathrm{C}$. 


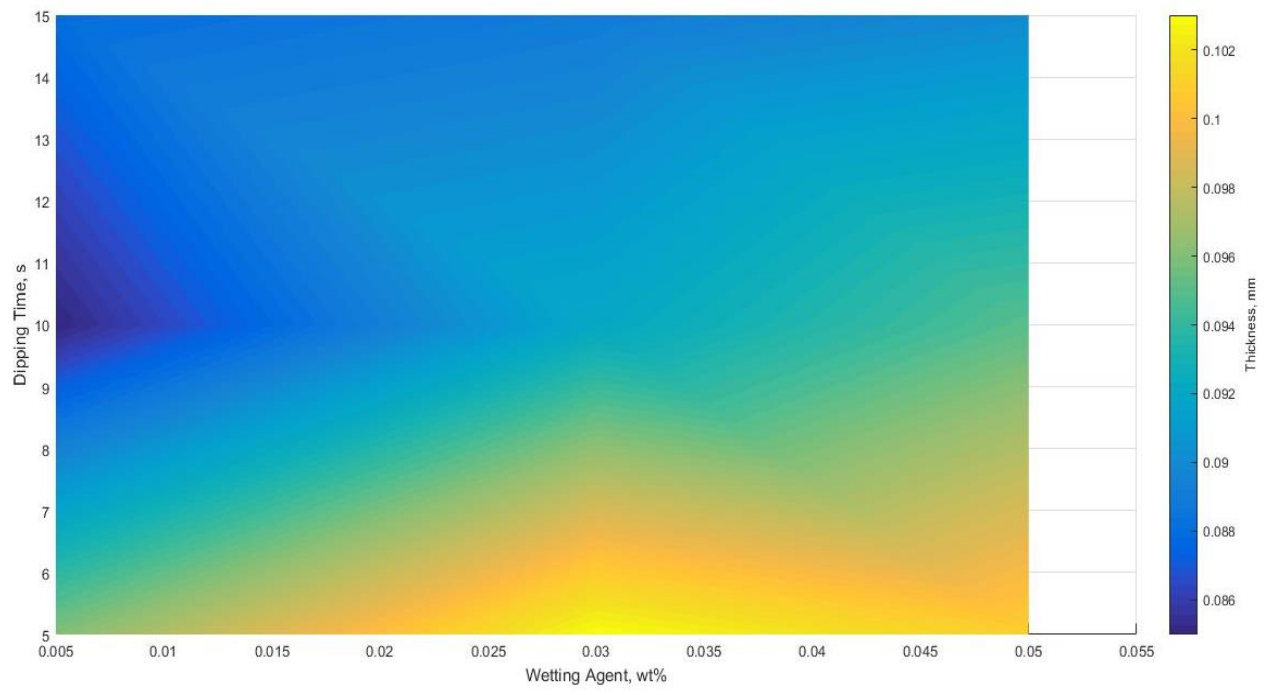

Fig. 15 Predicted time and wetting agent amount against glove thickness for $63^{\circ} \mathrm{C}$

\subsection{Verification Result}

Table 3 below shows the average result of the thickness and tensile strength as well as error percentage of the result. By referring to Table 3, the average thickness gloves that produced from the experiment was in the range of $0.09 \pm 0.004 \mathrm{~mm}$. The result did not achieve the targeted value of $0.1 \mathrm{~mm}$ for ASTM standard. Besides, there is having error about $11.33 \%$ lies in glove thickness result compared to targeted thickness. The reason of this error is mainly due to human error.

While the average tensile strength of glove produce at $19.480 \mathrm{MPa}$ is higher than ASTM standard of $18 \mathrm{MPa}$. This means that the gloves meet the requirement standard as the parameters suitable. Unfortunately, the optimised-parameters' latex samples was having a sticky surface, due to the inefficiency in dispersing the anti-tack agent throughout the mould. In order to avoid this sticky issue, adding more anti-tack agent into coagulant would be able to negate this issue.

Table 3: Error percentage compared to targeted thickness.

\begin{tabular}{|c|c|c|c|}
\hline $\begin{array}{c}\text { Average Thickness, } \\
\mathrm{mm}\end{array}$ & $\begin{array}{c}\text { Targeted Thickness, } \\
\mathrm{mm}\end{array}$ & Error Percentage, \% & $\begin{array}{c}\text { Average Tensile } \\
\text { Strength, MPa }\end{array}$ \\
\hline 0.09 & 0.1 & 11.33 & 19.480 \\
\hline
\end{tabular}

\section{Conclusion}

In conclusion, 5 seconds dipping time at $63{ }^{\circ} \mathrm{C}$ were chosen compared with 8 seconds dipping time at $63{ }^{\circ} \mathrm{C}$. With lower operating cost on time dipping and temperature, this parameter is expected to able to produce mass amount of glove with low number of uneven wall thickness issue. This would indirectly increasing the profit due to more glove can be sold instead of dispose or sold in lowered price for uneven wall thickness glove. As a result, the optimise parameter from this investigation are set at $0.0175 \mathrm{wt} \%$ of wetting agent and about 5 seconds dipping time at $63{ }^{\circ} \mathrm{C}$. The produced latex glove gave an average thickness of $0.09 \pm 0.004 \mathrm{~mm}$. Both sample $\mathrm{E}$ and sample $\mathrm{T}$ shows comparable 
functional group, and with an easier access in the market, sample $\mathrm{T}$ was chosen to conducted the optimisation test. However, this data will be further trial run in production line.

\section{References}

1. M.C. Ng, H. Ab-Samat, and S. Kamaruddin, Int. J. Eng. Sci., 2319-1813 (2013).

2. P. Cacioli, Rev. Fr. d'Allergologie d'Immunologie Clin., 37, 1173-1176 (1997).

3. E. Yip and P. Cacioli, J. Allergy Clin. Immunol., 110, S3-S14 (2002).

4. V.R. Gundabala and A.F. Routh, J. Colloid Interface Sci., 303, 306-314 (2006).

5. L. Chen and F. Wu, J. Saudi Chem. Soc., 18, 545-550 (2014).

6. L. Sikong, M. Masae, K. Kooptarnond, W. Taweepreda, and F. Saito, Appl. Surf. Sci., 258, 4436-4443 (2012).

7. J. George, K.T. Varughese, and S. Thomas, Polymer (Guildf)., 41, 1507-1517 (2000).

8. A. Elena, I. Gozescu, A. Dabici, P. Sfirloaga, and Z. Szabadai, "Organic Compounds FT-IR Spectroscopy", in: Macro To Nano Spectrosc., InTech, (2012). 